\title{
The effect of Covid-19 on the electronic payment system: usage level trust and competence perspectives
}

\author{
Mahmoud Odeh $^{1}$, Mohammad Yousef ${ }^{2}$ \\ ${ }^{1}$ Department of Management Information System, Zarqa University, Jordan \\ ${ }^{2}$ Independent Researcher, Jordan
}

\begin{tabular}{l} 
Article Info \\
\hline Article history: \\
Received Nov 12, 2020 \\
Revised Feb 27, 2021 \\
Accepted Mar 14, 2021 \\
\hline Keywords: \\
Clouding \\
Competence \\
Covid-19 \\
E-commerce \\
E-payment system \\
Microsoft business intelligence \\
NVivo
\end{tabular}

\begin{abstract}
Covid-19 has dramatically spread globally and dramatically made several effects in almost all sectors. Electronic commerce and electronic payment systems are important sectors which affected directly by the Covid-19 pandemic. Online markets and electronic payment systems have been recognized as one of the fastest-growing technology in the last decade even within normal situations. However, several factors may influence such growth, which many consider as barriers or enablers of using the electronic payment system. This study aims to shed the light on the influence of Covid19 on the electronic payment system from trust and competence perspectives. The study employed both qualitative and quantitative methodological approaches for data collection and analysis. The data was collected from 31 semi-structured interviews, 718 surveys, and annual reports. NVivo, Microsoft Visio, and Microsoft power business intelligence were used for the data analysis process. As a part of this study, a proposed framework has been developed which includes both technical and managerial parts.
\end{abstract}

This is an open access article under the CC BY-SA license.

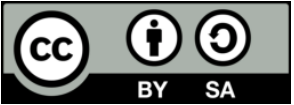

Corresponding Author:

Mahmoud Odeh

Department of Management Information System

Zarqa University, Jordan

Email: Modeh@Zu.edu.Jo

\section{INTRODUCTION}

In 2019-2020, the pandemic of Covid-19 has changed the approach of dealing with electronic payments even in developing countries such as Jordan. For instance, and before the spread of covid-19, the concept of digital financial services, including electronic payment systems, is very limited to several institutions that are specifically stationed in the Jordanian capital, Amman. This concept is absent from the arena of Jordanian society in its public and private sectors, especially areas far from the capital. Therefore, most commercial transactions between individuals and institutions are carried out in paper currency or paper checks hand in hand. However, in March 2020 the government of Jordan announced that it is strongly recommended to use electronic government services especially the electronic payment system to avoid the spread of Covid-19 in Jordan as it could be transferred through paper and metal currency. That is why the central bank of Jordan, in cooperation with a non-governmental organization called (Enjaz), participated in launching the financial literacy program using electronic means, the tools of which were developed through the (JOPACC) foundation, which is a non-governmental institution concerned with the innovation and development of electronic financial services. As it launched during the Covid-19 pandemic, through cooperation with the ministries of finance and digital economy, a package of programs, including "EFawateer.com", "mobile wallets services" and "new system for instant payment" a contribution from them to reduce dealing in paper currency between individuals and institutions, while at the same time activating 
electronic payment platforms more. However, despite the poor Jordanian technological infrastructure, cloud technology has been considered as an alternative for the electronic payment system (e.g. servers, storage devices, and in-house applications). Accordingly, cloud computing technology provides the ability to strengthen the weakness of infrastructure in Jordan and play a major role in transferring from physical payments to electronic payments. Furthermore, the government of Jordan announced that the private sector such as hypermarkets and restaurants should be focused on the electronic payment system instead of using physical currency. This is because the physical currency cloud plays a major role in spreading Coveid-19 between citizens as the virus may stay on such currency for more than five hours. Jordanian government forces strict roles for the delivery process to avoid the Covid-19 pandemic. Such strict roles include that the delivery service should be paid by online payment based on cloud servers monitored by the Jordanian government.

Based on the previous dissection, it could be argued that the use of electronic payment based on cloud technology has reached the highest level in 2020 because of the Covid-19 Pandemic. The social effect has greatly influenced the usage of electronic payment. The research problem in this study could be summarised into the low level of trust of using electronic payment system based on cloud technology as well as the limited frameworks available in the previous literature. While the research questions are as follows:

a) What is the effect of the Covid-19 pandemic on the usage level of electronic payment systems?

b) What is the effect of the Covid-19 pandemic on the trust factor of using electronic payment systems?

c) What is the effect of the Covid-19 pandemic on the competence level?

\section{THEORETICAL FRAMEWORK}

This study adopts the main points of both Clouding-based electronic payment system, trust and competence, which are based on several previous studies above the same topic and based on several models and figures. To provide a deep vision for the process of adopting a cloud-payment system, this study employed the diffusion of innovation theory (DOI) as a theoretical framework. The theory has been developed by professor Everett Rogers. It has been started through Roger's book diffusion in innovation in 1962. DOI theory has been improved by several editions and extensively used to explain the process of any innovative technology adoption. According to Rogers (2003, p.12), diffusion is defined as "the process in which an innovation is communicated through certain channels over time among the members of a social system". Accordingly, the DOI theory is mainly aimed to support both individuals and organizations in the process of the new adoption of innovative technology. DOI has elements: (1) innovation, (2) communication channels, (3) time, and (4) the social system.

The innovation could be defined as a new idea or any innovation practices created by individuals or organizations. However, it could be argued that the innovation itself should not be necessary to be new, as it could be adopted by individuals or organizations before but new for others. Communication channels are related to the process of knowledge sharing between organizations or individuals. Whereas, the time has mainly three aspects started by the innovation-decision, which contained five levels from the first knowledge to the process of adoption or rejection. The second factor of time refers to the innovativeness who could be earliness/lateness based on their background and resources. Third, the innovation rate refers to the number or percentage of adopters. Finally, the social system that mainly focuses on the innovation process as a unit of people, organization, groups, and actions.

\subsection{Electronic-payment system}

The development of electronic business means during the past decade has led to the rapid growth of electronic commerce, which has allowed many institutions to conduct business operations over the Internet. In the modern era, with an increase in the number of institutions and individuals that carry out commercial activities. The emergence of electronic commerce has generated many needs for new financial services that are not available in traditional payment systems, and thus the electronic payment systems have come to replace the traditional payment systems [1].

The electronic payment system is a set of linked elements, tools, and means of payment associated with facilitating the exchange of services and goods throughout websites. As the electronic payment systems provide ease in handling the various commercial exchange operations between the various parties. The use of electronic payment systems has many advantages and benefits for large institutions, either governmental or private, banks, industrial and service institutions, and individuals across the world. As it allows the payment system through effective and reliable electronic platforms to make payments efficiently, quickly, and with transparency in tracking transactions with less time and less cost and increasing confidence between the parties to the exchange commercial process [2]. 
The payment gateway is an essential element in the electronic payment models which considered as infrustracture for electronic commercial transactions to ensure that commercial exchange operations are saftly and to maintain joint security through electronic systems [3]. Secure socket layer (SSL) along with rivest-shamir-adleman (RSA) works to protect online communication by the following features: Server authentication, encryption and data/message integrity [4]. This system helps in securing the sale and purchase operations in addition to the personal information exchanged by encrypting personal information such as specific bank card details to ensure the safe transfer of information between the parties of the business transactions [3].

The technological development of electronic payment platforms includes various financial processes, accommodating all users, and high quality that enhances customer perceptions and expectations [1]. The following equation illustrates the effect of electronic payments system on the performance of the financial process, financial performance $=C_{0}+C_{1} E-$ payment $_{u}+C_{2} \cdot$ Control $_{t}+e_{u}$, Where financial performance is showing indicator of the business commercial sectors and is defined as the net profit margin of the financial sector [5]. The use of electronic payment systems also promotes significant cost savings as well as traditional transactions. For example, but not limited to, conducting financial transactions through automated teller machines (ATM), various payment cards, internet banking services (IBS), and various financial services via mobile phones [1].

The electronic payment system includes many features and advantages that distinguish it from the traditional payment system, such as confidentiality, availability, usability, security, authentications, and trustworthiness [6]. Not to mention time-saving, no time constraints, cost-effective, and fast exchanges of information are considered the most important advantages resulted using the electronic payment system [7] Also, electronic payment systems has several constructs that play a basic role in dealing with these models, such as: performance expectancy, effort expectancy, social influence, price value, awareness, security, privacy, and culture [8].

Digital payment services provided by financial institutions consist of: virtual point of sales, which consider secure, means to receive payment by using electronic payment types such as, Visa card and Master card [9]. A second factor is mobile phone system operators, which are considered universality, cost-effective, widely acceptable, and globally accessible [10]. Also, digital Wat It is an electronic wallet that makes empower for electronic payments by adding the essential data of all Visa cards, Master cards, or prepaid cards in the same secured cloud platform, which customers enable to securely add, store, update and cancel a large amount of card information from different financial institutions [9].

Technology acceptance model (TAM) factors and tools make a significant contribution to identify customer intention, and attitudes towards technology platforms use. Moreover, it set on two variables: perceived ease of use and perceived usefulness [11]. However, essential techniques in payment methods that utilize the cloud-systems correlate with technology acceptance model by Electronic-based transaction such as cyber cash and net bill as well as internet-based payment system like visa card [12].

\subsection{Trust and trustworthiness}

The trust factor is one of the most prominent factors that greatly affect the development and growth of an electronic business, especially electronic commerce. Most theories regarding trust are based on personal contact and traditional relationships. However, electronic business naturally lacks this important component. Thus, it is extremely difficult to create and/or maintain a high level of trust for electronic business platforms. Therefore, it is especially important to consider the level of protection and safety when designing electronic business platforms and verify the technical protection that has been developed to reduce the risks of exchange and transaction before addressing the issue of trust for users [2].

Trust is critical and a significant factor in all types of human and social relationships and interactions, as it is a major reason for individuals and companies to accept interaction with each other across the technology environment [13]. There are various definitions of trust from many perspectives as:(1) a set of specific beliefs, attitudes, intentions, behavior, and goal-oriented (trusting beliefs [13].; (2) it is a mixture of the basic elements such as reliability, validity, utility, credibility, and self-orientation, which are linked by different relationships in different forms [14].

Although the researchers' perspective on the concept of trust differs from different angles, there are major common factors between them, as follows [15].

a) The trust factor plays an important role, especially in a risky and/or uncertain environment.

b) Trust is the cornerstone on which to make bold decisions.

c) The relationship between trust and the two factors of knowledge and experience is governed by a positive relationship.

d) Trust is an inner feeling that is based on several concepts, values, and givens of an individual. 
Trust and trustworthiness were showed their importance in society nowadays with accompanying behaviors of economy, polity, and culture [16]. There is no difference between trust and trustworthiness but are complementary to each other, is that trust is confidence in or reliance on some person or quality, where confidence includes: belief, emotions, a tacit demand, a desire, and reciprocal activity [17]. While trustworthiness is the state or quality of being trustworthy or reliable, derivations of trustworthiness include the following main elements: consistency, competence, welfare, communication, integrity, and value alignment [18].

Figure 1 shows the main components, which include trust, credibility, reliability, and intimacy. There are many key elements that researchers have used in various mathematical methods to arrive at an equation that measures the level of trust of individuals and institutions. These include the following:

a) Credibility: It speaks to words and credentials [16]. Also, it is a positive distinctive of the communicator's which affects the approval of the believability of the message by the recipient. Trustworthiness and expertise is the main key to define credibility [14].

b) Reliability: Represent how others perceive the consistency of electronic actions and institution actions ${ }^{\text {ee }}$ connection with our words (integrity). Also, Performance includes the competence of Artificial Intelligence in completing tasks and finishing those tasks consistently and reliably [13].

c) Intimacy: At first glance, intimacy is a strange word to use in a business context. "What, I'm supposed to intimate with my clients?" In the sensation that being intimate means being familiar, unofficial, and emotionally connected [16]. It points out the safety feeling amount with the interacting objects [14].

d) Self-orientation: It is not referred to as selfishness; it is an important factor that combines with other trustworthiness equation factors to point out the amount of object's focus [14].

\section{THE TRUSTED ADVISOR*}
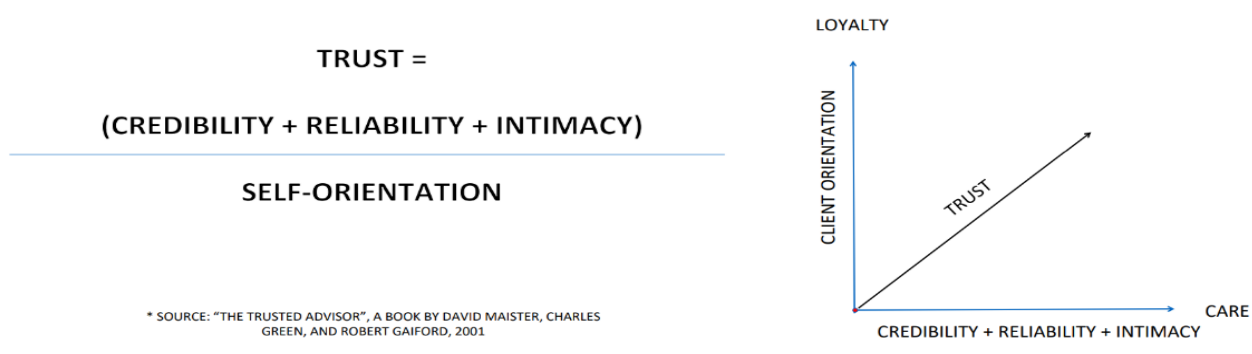

Figure 1. The trust advisor source: the trusted advisor ${ }^{\text {ee }}$ A book by David Maister, Charles green, and Robert, 2001

In the trust equation, the first three factors represent the numerator and the fourth factor represents the denominator. Mathematically, the higher the numerator value and/or the lower the denominator value, that leads the higher of trust value, which is required from this equation.

The trust value $T^{x}(\mathrm{t})$ represents a real number, which $(\mathrm{x})$ refers to honesty, cooperativeness, or community-interest [19]. Moreover, there are two types of trust observations: the first one called "Direct trust observations" which remarkable by the following formula:

$$
T_{j i}{ }^{x}=\frac{\text { Friends }(j) \bigcap \text { Friends }(i)}{\text { Friends }(j) \bigcup \text { Friends }(i)}
$$

Or

$$
T_{j i}{ }^{x}=\frac{\operatorname{Community}(j) \bigcap \operatorname{Community}(i)}{\operatorname{Community}(j) \bigcup \operatorname{Community}(i)}
$$

wheras $(j, i) \neq 0$, where formula (1) Using social friendship to characterize and formula (2) Considering community/group relationship. A second type called "Indirect trust observations "that represented by the following: 


$$
T_{i k}{ }^{x}=\frac{B T_{i k}^{x}(t)}{1+B T_{i k}^{x}(t)}
$$

where $T_{i k}{ }^{x}$ the probability of trust and B is the contribution of recommended trust.

Also, the researcher can classify trust through the following two factors:

a) Trust by the relation: measuring trust in a social network environment is a challenging task due to the wide range and mostly random nature of relationships on the network. On many social networking sites, when a user adds new friends into their social network, they are requested to specify the kind of relationship between them. This relationship can be specified by the following formula [20].

$$
T_{a, u}=\prod_{u}^{a} T_{a, b, c, \ldots, n, u}=T_{a, b} \times T_{b, c} \times \ldots \ldots \times T_{n, u}=T_{1} \times T_{2} \times \ldots \ldots \times T_{5} \times T_{6}^{n-5}
$$

Where $T_{1}$ to $T_{6}$, represent the trust weight of relationships respectively. This equation shows how to compute the trust between users a and $u$, who are separated by $n+1$ JUMPs through an intermediate user in the social network.

b) Trust by reputation: In addition to relationships, trust can be derived from the reputation of a user. The commendation of a known expert on a given topic will carry remarkable weight with other users, even if there are no social relationships between the user and the expert [20]. The trust by reputation between user a and user u can be evaluated based on the measured values of these attributes using Multiple Attribute Utility Theory as follows:

$$
T_{a, u}=a \frac{\sum P I}{\text { totpi }}+B \frac{\sum W T W P}{\text { totwtwp }}+Y \frac{\sum L F}{\text { totlf }}+\delta \frac{\sum N F}{\text { totnf }}+e \frac{\sum T}{\text { tott }}+\theta \frac{\sum_{i=1}^{n} G I C i}{\text { totgic }}
$$

"Where $\alpha+\beta+\gamma+\delta+\varepsilon+\theta=1$, and whereas, PI indicate personal information, WTWP referred to wall-to-wall posts, LF indicates the number of links among friends, NF referred the number of friends, $T$ represents the count of tags among user a and user $\mathrm{u}$, and GIC indicate the number of groups in common. In each term, the denominator tot represents the total quantity of that a particular attribute of this user" [20, p.9]

The trust factor has a great impact on electronic cloud services, and several symbols have been formulated in the form of a mathematical equation, and this equation is used in the feedback and evaluation of the elements of trust more efficiently [21].

$$
T_{r s}=\frac{\sum_{i=1}^{v} F_{c}(l, s)}{V(s)}
$$

where $\mathrm{V}(\mathrm{s})$ is all trust feedbacks given to the cloud service $\mathrm{s}$.

$F_{c}(l, s)=F(l, s) \times \operatorname{Erp}(l)$, whereas $F_{c}(l, s)$ is feedback for trust result and $\operatorname{Erp}(l)$ is Cloud Consumer's Experience aggregated weights.

\subsection{The competence and competency model}

Various definitions of competency are available. In the HR-XML Association Competencies Schema, competency is clarified as the following:

a) "Competence is a person's ability to perform a certain activity - quality, skills, and ability to do something competently. This notion emphasizes the intrinsic quality of humans, which allows him to submit a performance" [22, p.3].

b) An underlying characteristic of a person which results in an effective and/or superior performance in a job" and set that the competency includes "a motive, trait, skill, aspect of one's self-image or social role, or a body of knowledge which he/she uses [23].

c) Emerging behavior within a specialized domain in the shape of consistently demonstrated actions of an individual which are both minimally efficient in their fulfillment and effective in their results [24]. 
The competency model depends largely on the certainty that the other side is really qualified and highly credible, and looking at the competency model from the perspective that the (trustee) has a deep knowledge and the necessary experience and the skills required to fulfill the needs of the (trustor), when the confidence of individuals grows, they believe that the other party will act According to their expectations and thus will fulfill his commitment. In other words, competence is linked to the institution's ability to deliver on its promises [18].

The importance of defining competencies in society comes to the establishment of what is called a competency model that is a feature for a specific position, and this model can be used in many different fields and it greatly contributes, for example, to the development of human resources, employee recruitment, periodic remuneration operations, and continuous training. To keep abreast of the latest developments and to promote development programs. It is a key tool in assessing the employees, career planning, and talent management [23].

The competency model is very necessary to analyze the skills gap, and compare the available competencies and the required competencies, both at the level of different individuals and institutions. Moreover, the competency model greatly contributes to creating a development plan for individuals working in enterprises to eliminate the gap. Also, important variables must be taken into account during the development of the competency model through the use of dictionaries dedicated to skills and their development, and the identification of competencies and verification methods through several tools, including-surveys, interviews, focus groups [22].

A comprehensive management competency model indicates the necessity of evaluating the competency holistically - as the managerial competence is based on three basic pillars: the cognitive ability, skill in applying knowledge, and social maturity of each manager. The competency equation presented the following formula:

$$
\text { "HQ = } \mathrm{f}(\mathrm{SQ}, \mathrm{AQ}, \mathrm{KQ})
$$

Where:

$\mathrm{HQ}=$ Holistic competence

$\mathrm{SQ}=$ Social maturity, SQ = SQ1, SQ2, SQ3, SQ4,

$\mathrm{AQ}=$ Application (practical) skills, AQ= AQ1, AQ2, AQ3, AQ4, AQ5

$\mathrm{KQ}=$ Knowledge ability, KQ = KQ1, KQ2, KQ3, KQ4" [18, p.4].

However, this model consists of:

a) Social maturity, which means the willingness of an individual to take responsibility for developing his/her community.

b) Application (practical) skills, refers to a person's ability to perform a certain task, such as the surgeon's skill to perform surgery [23].

c) Knowledgeability relates to everything that an individual can learn through training courses and various educational systems including cognitive processes such as perception / cognitive awareness, continuous learning, social communication, and constructive thinking. It represents the theoretical understanding of something such as a new or updated method or procedure [22].

The issue of a competency model is measured by tools that individuals use to obtain their desires. Two factors can be used to measure the competency by the following formula:

$$
\zeta=\zeta_{1}+\zeta_{2}+\zeta_{3}
$$

Where:

$$
\begin{aligned}
& \zeta_{1}=B+B \zeta+v \\
& \zeta_{2}=B+2 B \zeta+v \\
& \zeta_{3}=B+3 B \zeta+v
\end{aligned}
$$

$\zeta$ Represent the competency model, and $\zeta_{1}+\zeta_{2}+\zeta_{3}$ indicate Customer satisfaction, Customer trust, and Customer loyalty [25]. 


\section{RESEARCH HYPOTHESES}

The subject of this research proposal revolves around how the effect of Covid-19 on the usage of electronic payment systems, trust factors, and competency.

a) Hypotheses 1: The pandemic of Covid-19 has a positive influence on the usage level of electronic payment systems.

b) Hypotheses 2: The pandemic of Covid-19 has a positive influence on the trust factor of using electronic payment systems.

c) Hypotheses 3: The pandemic of Covid-19 has a positive influence on the competence level.

\section{RESEARCH METHODOLOGY AND MAIN RESULTS}

This study employed the inductive-detective approach using quantitative and qualitative mixedmode methods. A total of 718 participants had successfully responded to the online survey. Besides, 31 semistructured interviews have been conducted with experts in information systems and e-marketing. Table 1 presents the characteristics of participants in the survey of this study. Whereas, Table 2 presents the profiles of participants in interviews.

Table 1. Characteristics of participants in the online survey

\begin{tabular}{lll}
\hline Characteristics & Categories & Total $(\mathrm{n}=718) \mathrm{N}(\%)$ \\
\hline Gender & Male & $412(57.4)$ \\
Governorate & Female & $306(42.6)$ \\
& North & $89(12.3)$ \\
& Middle & $367(51.3)$ \\
Age (years) & South & $262(36.4)$ \\
& $18-30$ & $246(34.2)$ \\
& $31-45$ & $318(44.5)$ \\
Educational level & $46-60$ & $149(20.7)$ \\
& $>60$ & $5(0.6)$ \\
& Secondary school or less & $146(20.3)$ \\
Monthly income & Diploma or bachelors & $513(71.5)$ \\
& High education (Master or Ph.D.) & $59(8.2)$ \\
& <poverty line & $64(8.9)$ \\
& $\geq$ Poverty line & $654(91.1)$ \\
\hline
\end{tabular}

Table 2. Interviewee profiles

\begin{tabular}{cclc}
\hline$\#$ & Code & \multicolumn{1}{c}{ Interviewee professional profile } & Years of experience \\
\hline 1 & V1 & Professor in marketing & 23 \\
2 & V2 & Expert in electronic business & 11 \\
3 & V3 & General manager in well-known website for online services & 26 \\
4 & V4 & Bank branch manager & 9 \\
5 & V5 & Bank team leader & 7 \\
6 & V6 & Professor in management information systems & 18 \\
7 & V7 & Professor in computer science & 19 \\
8 & V8 & Assistant professor in computer science & 4 \\
9 & V9 & Assistant professor in software engineering & 1 \\
10 & V10 & Associate professor in electronic commerce & 6 \\
11 & V11 & Bank senior manager & 12 \\
12 & V12 & Senior programmer in Well-known website for online products & 13 \\
13 & V13 & Assistant professor in management information systems & 3 \\
\hline
\end{tabular}

The data has been analyzed using several tools such as Microsoft business intelligence, NVivo, and Microsoft Visio. The results in this study are represented in frequency shapes and direct view of point analyzed by NVivo software.

\subsection{Covid-19 pandemic has a positive influence on using electronic payment and online shopping}

Even though the Covid-19 pandemic has a catastrophic effect on the economy in general, the results from this study show that it has a positive influence on online shopping, electronic payment, and cloud computing technology. Figure 2 shows that $77 \%$ of participants believe that Covid-19 consider as a major reason for raising the usage of electronic payment methods and online shopping. However, $12 \%$ of participants believed that there is no relation between the increase of usage of the electronic payment and Covid-19 and $11 \%$ of participants did not know if there is any relation exist or not. 


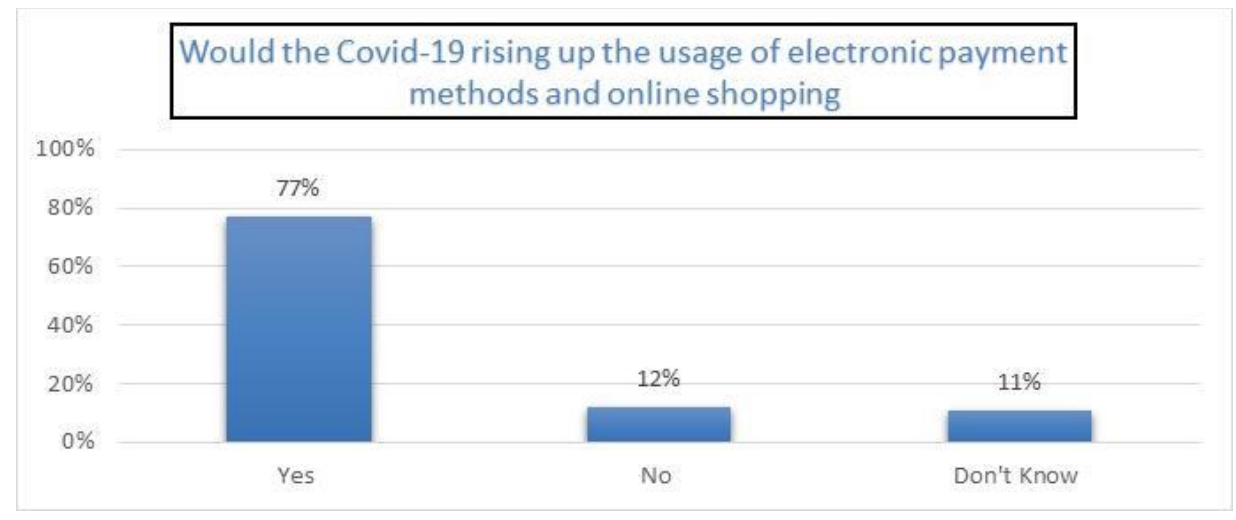

Figure 2. The influence of Covid-19 on the usage of electronic payment methods and online shopping

Supporting the argument of $77 \%$ of participants from the survey, most interviewees argued that there is a strong relation between Covid-19 and the online payment process. As one of the participants stated that:

"It is very clear that Covid-19 has changed the way of our life, especially the shopping habits. You can simply see this change. The electronic commerce websites have great traffic during the last five months"V3.

And other participants stated:

"Simply check the increasing wealth of stakeholders in E-Bay and Amazon. They gained billions of dollars during the last six months because of Covid-19" V5.

\subsection{Covid-19 pandemic has a positive influence on the trust of using electronic payment systems}

The term trust is normally using before the process of taking action against any innovation. Covid19 , however, enforces most people to take the risk of using the electronic payment approach and then decide to trust or not. According to Figure 3,56\% of participants in this study have been used the electronic payment system for the first time at the beginning of the Covid-19 pandemic. $23 \%$ of participants in this study argued that they have already using the electronic payment system and they already have the trust of using it. $21 \%$ of participants have been never used the electronic payment system and therefore they still cannot trust the usage of online payment methods.

One of the experts in marketing, who participated in this research argued that:

"Trust is one of the most complicated factors in electronic payment systems. In developing, we believe that most consumers prefer traditional physical markets because of the fear of hacking their bank accounts. Another reason could be that in online shops the quality of products cannot be checked. Finally, some faked comments from faked consumers about the high quality of products may have a negative influence on trust factor". V11

From the previous results, it could be argued that the Covid-19 has a positive influence over the trust factor of online payment as well as cloud-based payments. However, in developing countries the trust factor still one of the greatest challenges in using electronic payment and cloud technology.

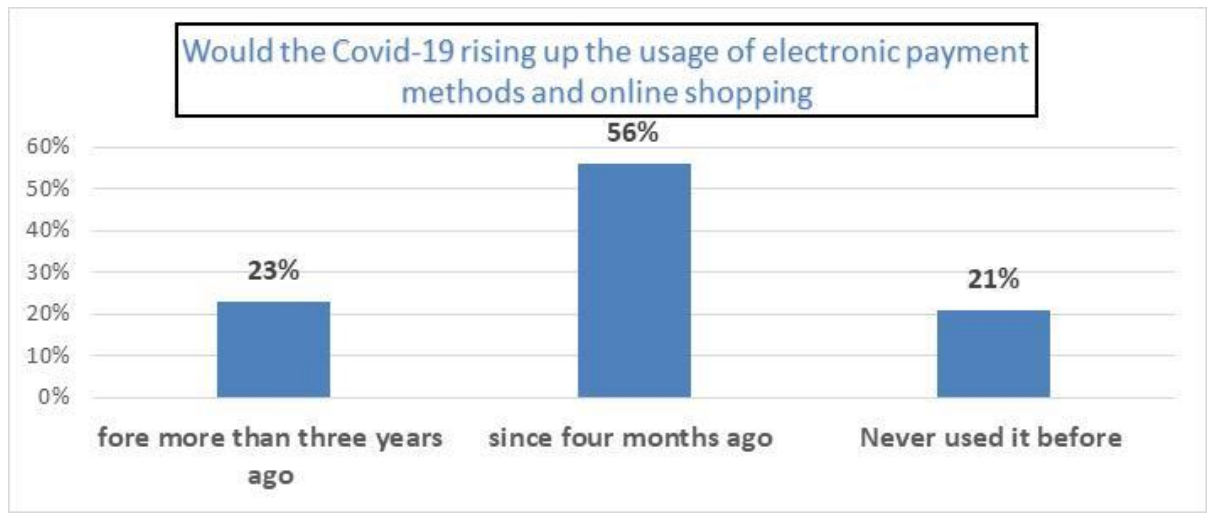

Figure 3. The influence of Covid-19 on the trust of using electronic payment methods and online shopping 


\title{
4.3. Covid-19 pandemic has a negative influence on competency
}

The traditional competitor of online shopping is the physical markets. Such a competitor enforces online markets to provide more offers with fewer prices to convince customers for purchasing products online. Physical markets usually provide a big sale with a high discount on several occasions. However, with Covid-19 the physical markets become unavailable especially during restrict days. According to the result of this study, Covid-19 has a negative influence on the competency factor. As the online market and delivery products become more expensive, took more time than usual, and with almost very low discount. Figure 4 shows that $41 \%$ of participants believed that Covid-19 has a negative influence on the online competency factor, while $16 \%$ believed that it has a positive influence, and $43 \%$ have no answer.

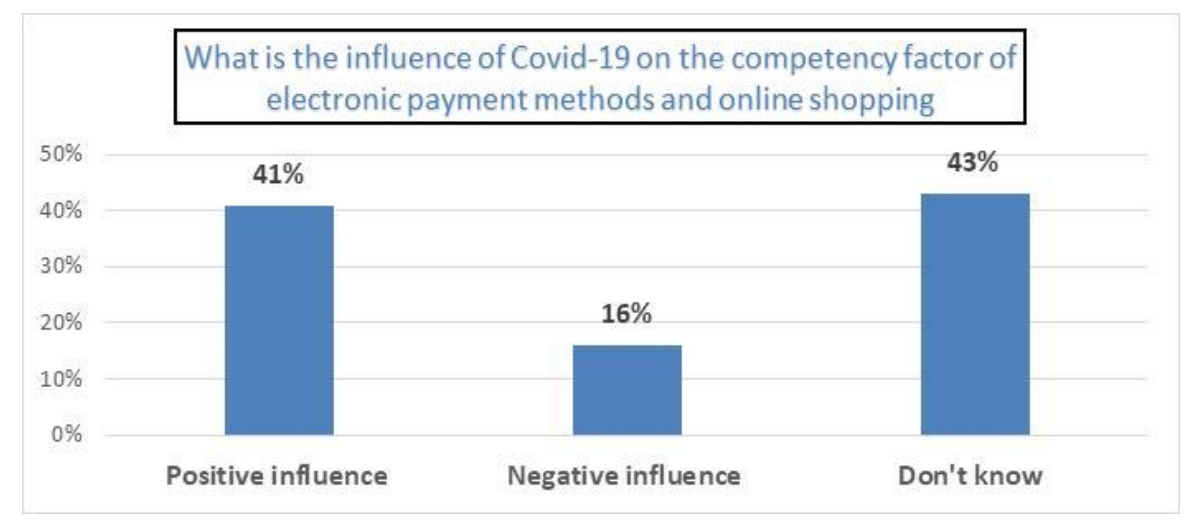

Figure 4. The influence of Covid-19 on the competency factor of electronic payment methods and online shopping

One of the participants in this study who work as an online sales manager in a well-known website stated that:

\begin{abstract}
"During the last three months, we received a considerable number of complaints about the delivery services and delivery time. This is expected as the traffic and orders on our website has dramatically increased. We did not focus on competency in this stage. The main focus is to finish the orders and close the complaining cases. In the last few months, we recognized that the number of employees is not enough to cover all this traffic". V13
\end{abstract}

Based on the results of this study, it could be argued that the Covid-19 has a negative influence on the competency of online orders as well as electronic payment systems. The high level of online orders enforces the online shops and websites to shed the light on completeness rather than perfection.

\section{FRAMEWORK}

\subsection{Managerial side and theoretical foundation}

According to Figure 5 the proposed framework of this study started with the trust factor and competency factor. These row factors have been merged with a cloud-based electronic payment process to develop the influence of these factors, which finally shaped with Covid-19 influence. The customer after such a framework may transfer to loyalty and satisfaction of using a cloud-based electronic payment system. The framework started with the trust factor, which merged with the competency factor. Such two factors may depend on a cloud-based electronic payment system as the cloud technology could provide a robust infrastructure with a pay-per-use business model as well as a high level of security, especially when using a trusted cloud service provider such as Amazon or Google.

\subsection{The practical side}

As a part of the framework, this study suggests an application that may use by online shopping websites to study the competency and trust factor, which may lead to loyalty and satisfaction. The application has been programmed by this study author to provide a theoretical proposed framework for the electronic payment system. Figures 6 and 7 presents part of the source code using in programming the framework application. 


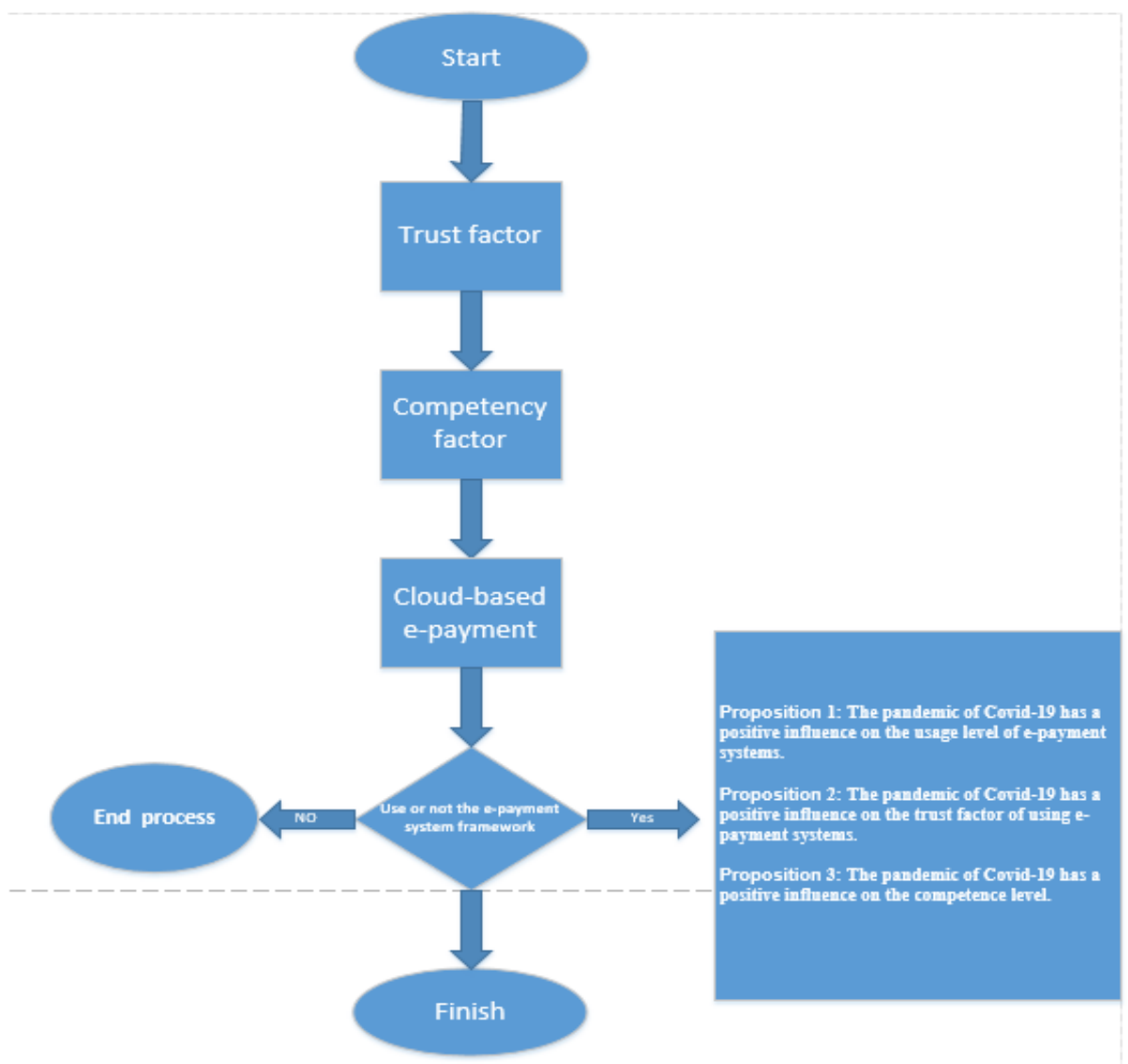

Figure 5. The proposed framework for a clouding-based electronic payment system

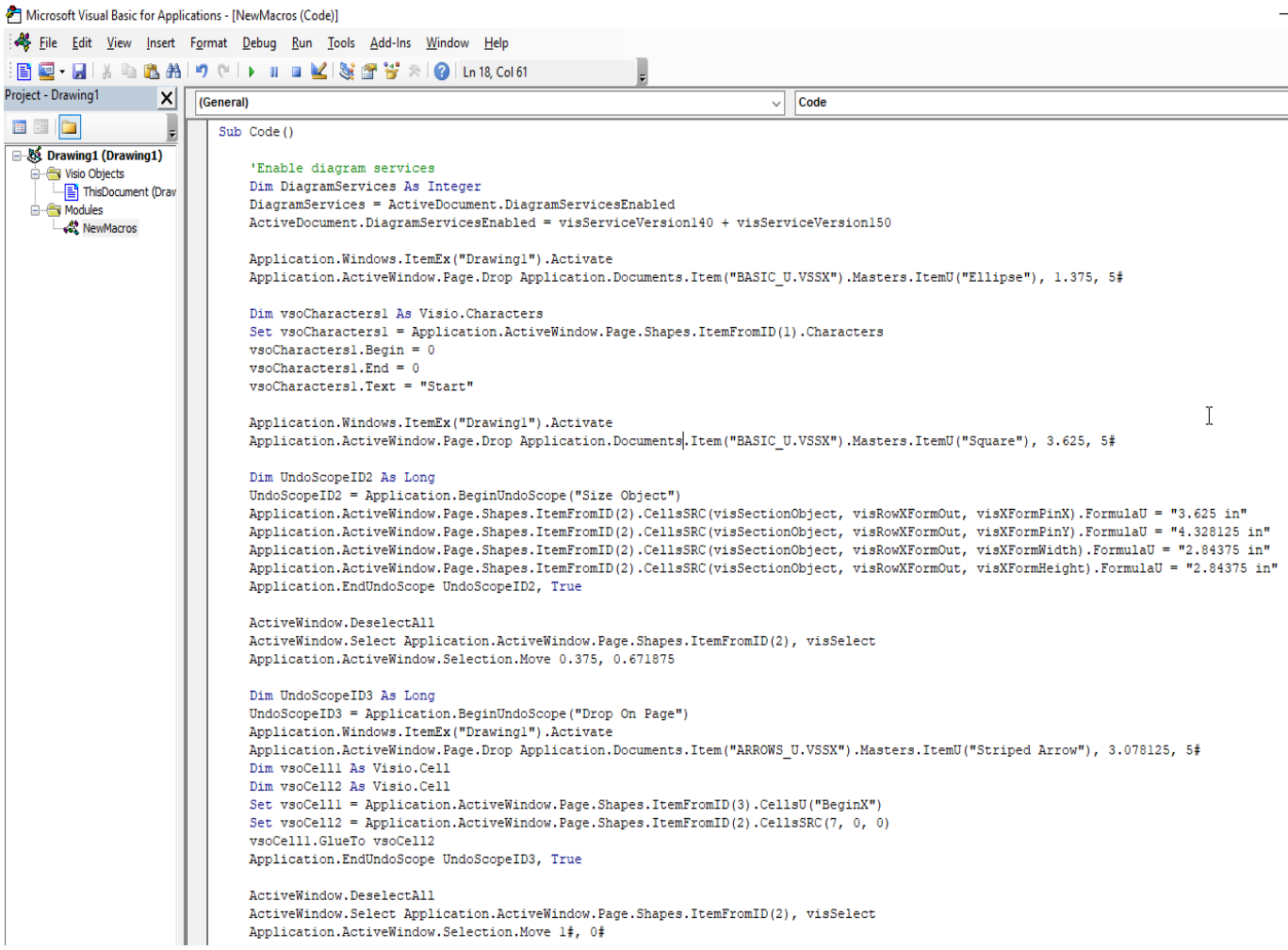

Figure 6. A sample of the source code for framework programming part 1 


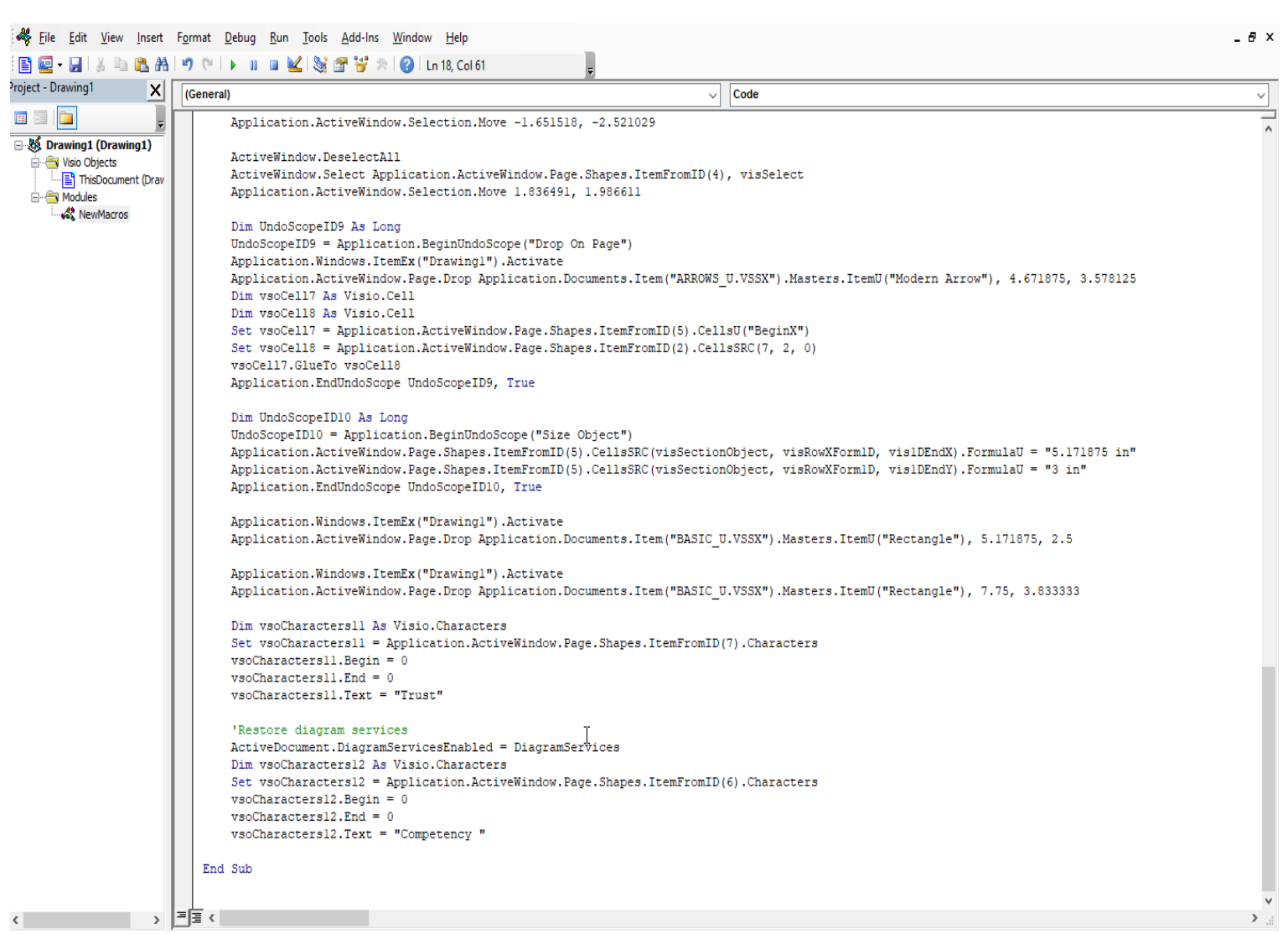

Figure 7. A sample of the source code for framework programming part 2

\section{CONCLUSION}

This study aimed to investigate the effect of Covid-19 on electronic payment systems. Such investigation took the perspectives of trust and competence factors. This study shows that the pandemic of Covid-19 has a positive influence on electronic payment systems with trust and usage perspectives. Whereases, Covid-19 has a negative influence on online shopping and electronic payment systems. Qualitative and quantitative methodologies have been employed in this study as a methodological approach. However, several limitations could be taken into consideration such as the ability to use the proposed framework in several sectors as well as the pandemic period of Covid-19 which could be an exceptional case. Finally, this article supports previous studies through a proposed framework, which has been suggested to improve the process of electronic payment based on trust and competence factors. Further studies are recommended to test the proposed framework in this research, which cloud helps in improving the electronic payment systems based on the cloud-based process.

\section{ACKNOWLEDGEMENTS}

This research is funded by the Deanship of Research in Zarqa University, Jordan.

\section{REFERENCES}

[1] Fatonah, S., Yulandari, A. and Wibowo, F.W., “A Review of E-Payment System in E-Commerce,” In Journal of Physics: Conference Series, vol. 1140, no. 1, p. 012033, 2018, doi: 10.1088/1742-6596/1140/1/012033.

[2] Emrah,O ;GUVEN,G, and Gizem; H., "The determinants of electronic payment systems usage from consumers' perspective," Economic research-Ekonomska istraživanja, vol. 30, no. 1, pp. 394-415, 2017, doi: 10.1080/1331677X.2017.1305791.

[3] Hassan, M.A., Shukur, Z. and Hasan, M.K., "An Efficient Secure Electronic Payment System for E-Commerce," Computers, vol. 9, no. 3, p. 66, 2020, doi: 10.3390/computers9030066.

[4] Oo, K.Z., "Design and Implementation of Electronic Payment Gateway for Secure Online Payment System," Int. J. Trend Sci. Res. Dev, vol. 3, pp. 1329-1334, 2019.

[5] Torki, L., Rezaei, A. and Razmi, S.F., "The Effects of Electronic Payment Systems on the Performance of the Financial Sector in Selected Islamic Countries," International Journal of Economics and Politics, vol. 1, no. 1, pp. 113-121, 2020. 
[6] Ali, N.N., Allan, M.S. and Azzam, Z.A., "The Impact of Total Quality Management (TQM) Dimensions on Achieving Competitive Advantage: Managerial Perspective of The Quality Department Staff at Five-Star Hotels," Case of Jordan, vol. 9, no. 2, pp. 2578-2587, 2020.

[7] Saikrishna, M.B., "Electronic payment: current scenario and scope for improvement," American Journal of Economics and Business Management, vol. 3, no. 2, pp. 35-44, 2020, doi: 10.31150/ajebm.v3i2.152.

[8] Al-Okaily, M., Lutfi, A., Alsaad, A., Taamneh, A. and Alsyouf, A., "The determinants of digital payment systems' acceptance under cultural orientation differences: The case of uncertainty avoidance," Technology in Society, vol. 63, p.101367, 2020, doi: 10.1016/j.techsoc.2020.101367.

[9] Yazici, M., "The impact of Covid-19 on the payment system," 2020.

[10] Duangphasuk, S., Thammarat, C. and Kungpisdan, S., "Mobile Payment: A Review," Journal Of Information Science And Technology, vol. 10, no. 2, pp. 10-18, 2020, doi: 10.14456/jist.2020.13.

[11] Vahdat, A., Alizadeh, A., Quach, S. and Hamelin, N., "Would you like to shop via mobile app technology? The technology acceptance model, social factors and purchase intention," Australasian Marketing Journal (AMJ), 2020, doi: 10.1016/j.ausmj.2020.01.002.

[12] Naeem, M., Hameed, M. and Taha, M.S., "A study of electronic payment system," In IOP Conference Series: Materials Science and Engineering, vol. 767, no. 1, p. 012008, 2020, doi: 10.1088/1757-899X/767/1/012008.

[13] Siau, K. and Wang, W., "Building trust in artificial intelligence, machine learning, and robotics," Cutter Business Technology Journal, vol. 31, no. 2, pp. 47-53, 2018.

[14] Abdullah, M.N. and Al-Chalabi, A.M., "Implementing Trust Management in Pervasive Computing Environment Depending on Trustworthiness Equation,” 2019, doi: 10.21275/ART20175171.

[15] Prasad, V.K., Shah, M., Patel, N. and Bhavsar, M., "Inspection of Trust Based Cloud Using Security and Capacity Management at an IaaS Level," Procedia computer science, vol. 132, pp. 1280-1289, 2018, doi: 10.1016/j.procs.2018.05.044.

[16] Ben-Ner, A. and Halldorsson, F., "Trusting and trustworthiness: What are they, how to measure them, and what affects them," Journal of Economic Psychology, vol. 31, no. 1, pp. 64-79, 2010, doi: 10.1016/j.joep.2009.10.001.

[17] Sutrop, M., "Should We Trust Artificial Intelligence?," Trames, vol. 23, no. 4, pp. 499-522, 2019, doi: 10.3176/tr.2019.4.07.

[18] Kharouf, H., Lund, D.J. and Sekhon, H., "Building trust by signaling trustworthiness in service retail," Journal of Services Marketing, 2014, doi: 10.1108/JSM-01-2013-0005.

[19] Bao, F. and Chen, I.R., "Dynamic trust management for internet of things applications," In Proceedings of the 2012 international workshop on Self-aware Internet of things, pp. 1-6, 2012, doi: 10.1145/2378023.2378025.

[20] Wei, C., Khoury, R. and Fong, S., "Web 2.0 Recommendation service by multi-collaborative filtering trust network algorithm," Information Systems Frontiers, vol. 15, no. 4, pp. 533-551, 2013.

[21] Noor, T.H. and Sheng, Q.Z., 2011, October. "Trust as a service: A framework for trust management in cloud environments," In International conference on web information systems engineering, pp. 314-321, 2011.

[22] Rojicek, M., "European Conference on Quality in Official Statistics (Q2016)," pp. 83-84, 2016.

[23] Skorková, Z., "Competency models in the public sector," Procedia-Social and Behavioral Sciences, vol. 230, pp. 226-234, 2016, doi: 10.1016/j.sbspro.2016.09.029.

[24] Swanson, R.A. and Holton III, E.F., "Theory of human resource development. Foundations of human resource development," vol. 2, pp. 97-111, 2009.

[25] Chu, P.Y., Lee, G.Y. and Chao, Y., "Service quality, customer satisfaction, customer trust, and loyalty in an ebanking context," Social Behavior and Personality: an international journal, vol. 40, no. 8, pp. 1271-1283, 2012, doi: $10.2224 / \mathrm{sbp} .2012 .40 .8 .1271$. 